\title{
Financial Analysis of Litchi (Litchi chinensis Sonn.) Production in Dinajpur District of Bangladesh
}

\author{
Rumana Akter $^{1} *$, M. Serajul Islam ${ }^{1}$ and Golam Rabbani ${ }^{2}$ \\ ${ }^{1}$ Dept. of Agricultural Economics, Bangladesh Agricultural University, Mymensingh-2202, \\ Bangladesh; ${ }^{2}$ Dept. of Economics, Hajee Mohammad Danesh Science \& Technology University, \\ Dinajpur, Bangladesh
}

*Corresponding author and Email: rumanaakterrita4013@gmail.com

Received: 28 October 2016

Accepted: 12 December 2016

\begin{abstract}
The present study was conducted in 2015 to examine the profitability of litchi orchard production at Dinajpur sadar upzila in Dinajpur district where litchi orchards are generally leases out for 1 to 6 years by the owners known as "Deed". In total 312 litchi orchard trees of which 254 were Bombai, 40 Madrazi, 20 China-3, 2 China-2 and 3 were Bedana, were selected to estimate the BCR, NVP and IRR of litchi production. The litchi trees were 18 to 22 years old. Project appraisal techniques and sensitivity analysis was done by using primary data to determine cost and benefits from litchi production. The study revealed that individual's investment on litchi production is profitable. The study also found that in producing litchi Benefit Cost Ratio (BCR), Net Present Value (NPV) and Internal Rate of Return (IRR) were 1.93, Tk. 1643896 and Tk. 1230, respectively. Sensitivity analysis suggested that the investment in litchi production is profitable even for $10 \%$ increase in operating and maintenance cost or $10 \%$ decrease in gross benefit.
\end{abstract}

Keywords: Litchi, cost benefit ratio, net present value, internal rate of return.

\section{Introduction}

Establishment of an orchard is a long term investment where a careful planning and management is essential to ensure economic return (Marini, 1997). Litchi (Litchi chinensis Sonn.) orchard is no exception in this regard. To establish an orchard and to analyse the production and return, knowledge on investment costs analyses is needed which help growers in assessment of the profitability and evaluate future ventures. In 2013-2014, the total area of cultivation and production of litchi were about 4602 acres and 67371 metric tons, respectively in Bangladesh (BBS, 2014). The nutritional value of litchi places it on the crest of our edibles. This fruit contain vitamins and minerals in large quantities.

Litchi has long been cultivated as a very popular fruit in Bangladesh. It has also a long history of acceptance in China and many parts of the Southeast Asia. The cultivated litchis have been originated in the regions of southern China, northern Viet Nam and Malaysia. At present China, Taiwan, Thailand, India, South Africa, Madagascar, Mauritius and Australia are major litchi producing countries in the world (Singh et al., 2012). In Bangladesh, the leading litchi growing districts are Dinajpur, Rajshahi, 
Rangpur, Jessore, Pabna, Chittagong, Dhaka, Sylhet and Mymensingh. A surplus production of litchi in our country might open an opportunity to export our fruits to others countries for earning foreign currency. Several studies have been conducted on production, growth, disease and pest infestation of litchi production, but there is no adequate study on financial analysis. It has long been demanded to study the profitability of litchi production and therefore, the present study was undertaken. The outcome of present study would help the growers, retailer, traders, consumers, extension workers and researchers in their efforts for the improvement of production and marketing of litchi in Bangladesh. The specific objective of this study was to assessment of the profitability of investment in litchi orchard from the view point of individual investor.

\section{Methodology}

\subsection{Data Sources}

The present study was based on primary data collected from litchi orchard owners in Dinajpur district from March to May 2015. Primary data were collected through direct interviews by making personal visits were made by the researcher to the selected litchi growers. . A multistage sampling procedure was followed to select litchi growing areas. In the first stage, one litchi growing district (Dinajpur) with two Upazilas (Dinajpur Sadar and Kaharole) was selected purposively. In the second stage, two villages from each Upazila were selected randomly. Finally, a total of 60 were selected from the collected lists by adopting simple random sampling method from each village.

The main purpose of the survey was to collect and analyse field level costs and returns data from the litchi orchard owners. Average values of cost and benefit were used. For this analysis, five-year production period of litchi orchard was considered (Growers' age limit of 18 to 22 year was given priority). These data were required to make future projection for the value of inflows and outflows over the life of a litchi tree to assess the profitability of the litchi orchard owners. Preliminary observation showed that farmers in Sadar and Kaharole Upazila of Dinajpur district are more interested in itchi production rather than other crops because of higher profitability of litchi production then other crops. Therefore, the aforementioned study areas were purposively chosen. In this study, 5.75 acres of land with 312 litchi trees was selected.

In the study area, different varieties of litchi like, Bombai, Bedana, Madrazi, Chaina-2, Chaina-3, and Mozaffari etc. are produced. But, because of its higher production and good taste, Bombai is more popular than any other varieties. However, Bombai, Bedana, Madrazi, Chaina-2, and Chaina-3 varieties were selected for this study.

The data collected following different methods were coded, summarized and processed for the analysis. To meet-up the objectives of the study the following three discounting methods of project appraisal technique were used.

\subsection{Theoretical framework}

2.2.1 Benefit cost ratio (BCR): The $B C R$ is a relative measure, which is used to compare present worth of costs. The BCR is estimated by dividing the sum of present worth of gross benefit by the sum of the present worth of gross costs.

2.2.2 Net present value (NPV): The NPV is an absolute measure, which estimates the project net present worth. NPV is obtained by deducing the present worth of cost from the present worth of benefits. Accept all projects when NPV is greater than zero (0) when discounted at opportunity cost of capital.

2.2.3 Internal rate of return (IRR): The IRR is defined, as the average earning power of the money invested in a project over the project life. The IRR is that discount rate, which just makes the NPV of project equal to zero, and the BCR equal to 1 (Miah, 1987). 
Mathematical Framework of the selected discounted measure is as follows:

$$
\begin{aligned}
\mathrm{BCR} & =\frac{\sum_{t=1}^{n} \frac{B_{t}}{(1+i)^{t}}}{\sum_{t=1}^{n} \frac{C_{t}}{(1+i)^{t}}} \\
\mathrm{NPV} & =\sum_{t=1}^{n} \frac{B_{t}-C_{t}}{(1+i)^{t}}
\end{aligned}
$$

The IRR is that discount rate $\mathrm{i}$, the formula of internal rate of return is, IRR $=$ Lower discount rate + Difference between the discount rate

$\mathrm{X}(\overline{\text { Sum of the present worth of incremental net benefit streams (cash flow) at two discount rate, sings ignored }})$

Where,

$$
\begin{aligned}
& \mathrm{B}_{\mathrm{t}}=\text { Benefit in each year (Tk./Year) } \\
& \mathrm{C}_{\mathrm{t}}=\text { Cost in each year (Tk./Year) } \\
& \mathrm{t}=1,2, \ldots \ldots \ldots, \mathrm{n} \\
& \mathrm{n}=\text { Number of years } \\
& \mathrm{i}=\text { Interest (discount) rate }
\end{aligned}
$$

Table 1. Study design and distribution of sample of litchi growers

\begin{tabular}{llll}
\hline District & Upazila & Village & Number of litchi growers \\
\hline \multirow{3}{*}{ Dinajpur } & Dinajpur sadar & Shunderban village & 15 \\
& & Shadarpur village & 15 \\
& \multirow{2}{*}{ Kaharole } & Shundarpur village & 15 \\
& & Dhonikgram village & 15 \\
\hline
\end{tabular}

Only financial analysis was followed for this study. For this reason, all costs and benefits were determined in local currency (Taka) using either farm gate prices or the prices at the point for first sale. For this study the prices at the point for first sale was chosen. The financial analysis from litchi orchard owner's point of view has been performed considering both cash cost and cost of family supplied inputs assuming that all inputs were purchased.
The cost of litchi orchard on the view point of individual investor can broadly be classified under the following two heads: (a) Investment cost; and (b) Operating and maintenance cost. For choosing discount rate the available literatures (Miah and Hadaker, 1988) suggest that in most developing countries the opportunity cost of capital between 8 to 15 percent. According to the manager of Bangladesh Krishi Bank (BKB), BAU Branch, Mymensingh had the 
leading rate of agriculture (production) loan of 11 per cent during the study period. Thus, a per cent discount rate was chosen for the appraisal of thresher projects.

\section{Results and Discussion}

\subsection{Cost of Litchi orchard considering it as an agricultural project}

In the study area, it was observed that maximum respondents used to lease in or out their litchi orchard for 1 to 6 years. The owners of litchi orchard are not directly involved in litchi production. This process of leasing is known as 'deed' in local language. One person or a group of persons who take lease of the litchi orchard is known as 'party' locally.

\subsection{Investment Cost}

In the study area, the farmers have no written record on the cost and benefit of litchi production. Therefore, they replied from their own memory. The parties pay a fixed amount of money to the litchi orchard owner for this period and take the whole ownership of the litchi orchard. The total amount of lease money which the respondent farmer paid to the orchard owner was considered as an investment cost. It was Tk. $13,50,000$ for five years tenure.

\subsection{Operation and Maintenance Costs}

In the litchi orchard the operating and maintenance cost include the expenditures related to protection of litchi orchard from thief, fencing around the garden, fertilizer application as and when needed. This cost depends on the amount of litchi flower, if the number of flower is more the cost become more and it also gives more benefit. The operational and maintenance costs are shown in Table 2. From the analysis of data the total operating and maintenance cost is Tk. 148124.

\subsection{Benefits Earned From the Project}

Benefits were derived on the basis of field level data. Among the 312 litchi trees there were different varieties e.g. 254 are Bombai, 40 are Madrazi, 20 are China-3, 2 are Chaina-2 and 3 are Bedana. Some litchi varieties bear the criteria of alternative bearing. Among these varieties, Bombai and Madrazi varieties bear fruits every year. So, in this study only these two varieties were taken to calculate the benefit of 5 years project of litchi which is shown in Table 3.

Table 2. Total operating and maintenance cost of the litchi orchard

\begin{tabular}{clc}
\hline SL No. & Cost items & Amount (Tk.) per orchard \\
\hline 1 & Cost of human labour & 51920 \\
2 & Cost of fertilizer & 2336 \\
3 & Cost of pesticide & 25000 \\
4 & Cost of irrigation & 6700 \\
5 & Cultural and management operation & 62168 \\
\hline & Total & 148124 \\
\hline
\end{tabular}

Table 3: Benefits Earned from the litchi project

\begin{tabular}{clcccc}
\hline $\begin{array}{c}\text { SL } \\
\text { No. }\end{array}$ & Types of litchi & Number of trees & $\begin{array}{c}\text { Quantity in } \\
\text { thousand/tree }\end{array}$ & $\begin{array}{c}\text { Price per thousand } \\
(\text { Tk.) }\end{array}$ & Total (Tk.) \\
\hline 1 & Bombai & 254 & 1.2 & 2500 & 762000 \\
2 & Madrazi & 40 & 2.5 & 1600 & 160000 \\
\hline & & & Total & 922000 \\
\hline
\end{tabular}




\subsection{Discount Rate}

The result of cost-benefit analysis is highly sensitive to the discount rate, the choice of appropriate discount rate, therefore, plays a vital role in the appraisal of a projects. Unfortunately, interest rate policy for rural credit is highly complex and debatable issue in the LDCs such as Bangladesh (Rashid, 1993). The policy is based on not only economic criteria but also on sociopolitical factors.

\subsection{Calculations of BCR, NPV and IRR}

Table 4 shows the BCR, NPV and IRR of important in litchi production. In financial analysis, interest is centred on the individual farm or unit. The main purpose is to determine the profitability of an individual project. Thus, the analysis gives a measure of the attractiveness of a project to an individual entrepreneur.

It can be seen from Table 3 that BCR is greater than 1 or unity NPV is positive though it is a highly profitable project, and IRR is very high. These results indicate that investment on litchi orchard is highly profitable.

\subsection{Sensitivity Analysis}

"Reworking an analysis to see what happens under these changed circumstances is called sensitivity analysis" (Gitinger, 1982). The aim is to see the profitability under the changed circumstances. Sensitivity analysis shows how the profitability of the projects changes with changes in the value of any variable/variables in the discounted cash flow analysis.

\subsection{Effects of Sensitivity Analysis on Litchi Orchard Project}

Form financial analysis which was stated earlier it is proved that the litchi orchard is a source of great profit. At first, sensitivity analysis was conducted on the assumption that investment cost of the projects would remain the same, however, what would happen if only operating and maintenance cost costs increase by 10 percent. In second case, sensitivity analysis has been conducted based on the assumption that all cost would remain the same, then what will happen in the profitability if gross benefit is decreased by 10 percent due to fall in production of litchi for natural hazard or fall in price of litchi. Under the changing circumstances, the sensitivity analysis will reflect the change of litchi production.

Table 4 indicates that $\mathrm{BCR}$ is 1.87 which is greater than 1 or unity, NPV is positive that is Tk. 1589149 and IRR is 123.24 percent. Those results suggest that investment on litchi orchard is profitable even if the operating and maintenance cost increase $10 \%$.

Table 5 indicates the results which explain that litchi production is profitable even if the gross benefit is reduced by $10 \%$.

Table 4. Summary result of the financial analysis

\begin{tabular}{clc}
\hline SL No. & Discounted measures & 5 years project of litchi \\
\hline 1 & Benefit-cost ratio (BCR) at 11\% & 1.93 \\
2 & Net Present Value (NPV) at 11\% (Tk.) & 1643895.69 \\
\hline 3 & Internal Rate of Return (\%) & 129.63 \\
\hline
\end{tabular}

Table 5. Summary result of sensitivity analysis considering 10 percent increase in operating and maintenance cost

\begin{tabular}{clc}
\hline SL No. & Discounted measures & 5 years project of litchi \\
\hline 1 & Benefit-cost ratio(BCR) at $11 \%$ & 1.87 \\
2 & Net Present Value (NPV) at $11 \%(\mathrm{Tk})$. & 1589149 \\
\hline 3 & Internal Rate of Return (\%) & 123.24 \\
\hline
\end{tabular}


Table 6. Summary result of sensitivity analysis considering 10 percent decrease in gross benefit

\begin{tabular}{clc}
\hline SL No. & Discounted measures & 5 years project of litchi \\
\hline 1 & Benefit-cost ratio(BCR) at 11\% & 1.74 \\
2 & Net Present Value (NPV) at 11\% (Tk.) & 1303124 \\
\hline 3 & Internal Rate of Return (\%) & 94.81 \\
\hline
\end{tabular}

\section{Conclusions}

While agricultural products had increased manifolds, it is showing signs of diminishing marginal return. Given the scarcity of cultivable land and a still growing population, land use and cropping intensity are approaching a maximum. Considering BCR, NPV and IRR based on full cost basis, the present results revealed that investment on litchi orchard project is profitable. Following sensitivity analysis it may be concluded that investment on litchi orchard production project is profitable.

\section{References}

BBS, 2014. Bangladesh Bureau of Statistics, Statistical Year Book of Bangladesh, Agriculture Statistical Wing, Ministry of Planning, Govt., of the Peoples Republic of Bangladesh, Bangladesh, 154 p.

Gittinger, J. P. 1982. Economic Analysis of Agricultural Projects. $2^{\text {nd }}$ edn, The Johns Hopkins University Press, Baltimore and London, 361p.

Marini, R.P. 1997. Growing peaches and nectarines in Virginia, Virginia cooperative extension. Virginia Tech. Virginia State University. Publication 422-019.
Miah, M. T. H. 1987. Appraisal of Deep and Shallow Tube-well Irrigation Project in the Tangail District in Bangladesh. MEc Dissertation, Department of Agricultural Economics and Business Management, University of New England, Australia.

Miah M. T. H. and Hardaker J. H., 1988. Benefit Cost Analysis of Deep and Shallow Tubewell Projects in Tangail District in Bangladesh. Bangladesh Journal of Agricultural Economic. XI (1):1-29.

Rashid, M.H. 1993. A comparative analysis of deep tubewells with buried pipe and deep tubewells with open channel irrigation system in a selected area of sakhipurthana of tangail district, MS thesis, Bangladesh Agricultural University, Mymensingh, Bangladesh.

Singh, G., Nath, V., Pandey, S. D., Roy, P. K. and Singh, H. S. 2012. The Litchi, Food and Agricultural Organization of the United Nations, New Delhi, India. 76-78. (http://tmnehs.gov.in). 